\title{
HEALTH-RELATED QUALITY OF LIFE AMONG DISPENSARY OBSERVATION PATIENTS WITH CHRONIC ILLNESS IN BULGARIA
}

\author{
Teodora Dimcheva, ${ }^{1}$ Boryana Levterova, ${ }^{2}$ Desislava Bakova, ${ }^{3}$ Nonka Mateva ${ }^{4}$
}

\begin{abstract}
:
Introduction: The prevalence of chronic non-communicable diseases (NCDs) worldwide acquires epidemic dimensions. In Europe, five nosological groups (diabetes mellitus, cardiovascular disease, cancer, chronic respiratory diseases and mental disabilities) constitute $77 \%$ of NCDs and cause about $86 \%$ of deaths in the region.

Objectives: This study aimed to assess the quality of life in patients with chronic non-communicable diseases under dispensary observation.

Methods: The pilot cross-sectional study was performed among adult with chronic diseases in primary care practices in the Plovdiv district (the second largest in Bulgaria) from May to June 2013.

Results: A total of 200 adults with chronic diseases participated in the study. The mean age was 55.6 years (range 25-95, standard deviation (SD) 16.9). The most common chronic diseases in our study were cardiovascular $51 \%$ (ischemic heart disease, hypertension, etc.), followed by endocrinology diseases (23\%). There was statistically significant differences in the assessments of "general health" in different groups of participants by gender $(\chi 2=16.65, \mathrm{P}<0.002)$, age $(\chi 2=12.57, \mathrm{P}$ $<0.05)$ and social status $(\chi 2=28.54, \mathrm{P}<0.0001)$.

Conclusion: The subjective assessment of health is a factor that has a strong impact on the quality of life of patients and is an important component in evaluating the effectiveness of provided health care for patients with chronic non-communicable diseases.
\end{abstract}

JEL Classification Numbers: I120, I140; DOI: http://dx.doi.org/10.12955/cbup.v5.1049

UDC Classification: 614.4

Keywords: Health Related Quality Of Life; Chronic Non-Communicable Diseases (NCDs); Bulgaria

\section{Introduction}

The prevalence of chronic non-communicable diseases (NCDs) worldwide acquires epidemic dimensions. The most common NCDs are cardiovascular diseases, cancer, chronic respiratory diseases and diabetes mellitus. According to the World Health Organization (WHO) - 3/4 of them occur in lowand middle-income countries, and over 16 million people are getting sick before the age of 70 (WHO, 2014; Lim et al., 2012).

Chronic diseases are defined as "diseases of long duration and slow progression" (WHO, 2008) or "conditions or symptoms that once acquired cannot be removed after 3 months or more" (Goodman et al., 2013).

In Europe, five nosological groups (diabetes mellitus, cardiovascular disease, cancer, chronic respiratory diseases and mental disabilities) constitute $77 \%$ of NCDs and cause about $86 \%$ of deaths in the region (Busse et al., 2010). Bulgaria is not an exception to this alarming trend. In our country, NCDs cause $80 \%$ of deaths with diseases of the circulatory system being the most prevalent $(67.5 \%)$, followed by malignant neoplasms with $(15.1 \%)$, diabetes mellitus $(8.3 \%)$ and others (Mateva \& Nonchev, 2015).

Health is the most comprehensive basic category in medicine and healthcare. The WHO defines health as "a state of complete physical, mental and social well-being and not merely the absence of disease or infirmity" (Official Records of the World Health Organization, no. 2, p. 100, 1948). In recent years WHO could add this definition the person's ability to maintain "productive socially and economically life" (Nutbeam, 1998).

The concept of Health-Related Quality Of Life (HRQOL) and its determinants have evolved since the 1980s to encompass those aspects of overall quality of life that can be expressly indicated to affect health. On the individual level, HRQOL incorporates physical and mental health perceptions and their correlations such as health risks, functional status, social support, and socioeconomic status (CDC,

\footnotetext{
${ }^{1}$ Public Health Faculty, Medical University of Plovdiv, Bulgaria, tdimcheva@ meduniversity-plovdiv.bg

${ }^{2}$ Faculty of Public Health, Medical University of Plovdiv, Bulgaria, boriana_levterova@abv.bg

${ }^{3}$ Faculty of Public Health, Medical University of Plovdiv, Bulgaria, desislavabakova@abv.bg

${ }^{4}$ Public Health Faculty, Medical University Plovdiv, Bulgaria, nonka.mateva@abv.bg
} 
2000). On the community level, HRQOL includes community-level resources, conditions, policies, and practices that impact a population's health (CDC, 2000; Dimcheva et al., 2015).

Health-related quality of life representing a person's subjective assessment of their sense of well-being and ability to perform social roles has been well accepted as a health indicator in medical interventions or health surveys. The HRQoL of patients with a single chronic disease has been explored in primary care (Fortin, 2004).

The implementation of appropriate tools for assessing the quality of life can find those areas of health NCDs which require closer scrutiny from health professionals. Instruments to measure QoL have the potential to identify specific and common unmet health needs of the population level (Levterova et al., 2014).

The aim of this study was to assess the quality of life in patients with chronic non-communicable diseases under dispensary observation in Plovdiv, Bulgaria, through an original questionnaire.

\section{Material and Methods}

A pilot cross-sectional survey, including the original questionnaire, was performed among adults with chronic diseases in primary care practices in Plovdiv district (the second largest in Bulgaria) from May to June 2013.

We selected patients from the primary care practices under contract to the Regional Health Insurance Fund Plovdiv. Inclusion criteria in the study were: age over 18 years old and subject to dispensary chronic non-communicable diseases according to Ordinance № 39 for prophylactic examinations and dispensary/ 16.11.2004 Ministry of Health of Bulgaria. An exclusion criteria included: patients with cognitive damage and inability to self-complete the questionnaire.

Additionally, 12 medical experts with extensive experience in the care of patients with chronic disease completed an open ended questionnaire in which they listed items that have a significant impact on the quality of life of patients with NCD; the importance of each item was ranked on a five point scale where 1 was the least important and 5 was the most important. Interviews with 16 patients with chronic disease were carried out (two focus groups of eight patients each) which supplemented the list of items for the initial questionnaire. We constructed appropriate questions for each item identified for the questionnaire, and specified response options using five point scales, ranging from the worst (1) to the best (5) possible function. The final questionnaire included 54 items divided into several groups.

The study was approved by the Research and Ethics Committee of the Medical University-Plovdiv. The study was in compliance with the Declaration of Helsinki. After informed consent was obtained, all participants were given the questionnaire and questions on socio-demographic information (age, sex, and ethnicity, level of education, employment status and marital status) and type of chronic disease.

Statistical analyses was performed using the SPSS 17.0 software (SPSS, Inc., Chicago, IL). Statistical significance was set at $\mathrm{p}$ value $<0.05$ for the data analysis.

\section{Results and Discussion}

Of the 200 patients recruited, 97 agreed to participate, representing a response rate of $48.5 \%$. Fifteen questionnaires were deleted because some data was missing. Among the 82 eligible respondents, 75.6 $\%$ were women. The mean age was 55.6 years old (range 25-95, standard deviation (SD) 16.9). The characteristics of the sample are shown in Table 1.

All patients had a confirmed diagnosis, according to the International Classification of Diseases (icd10) and were liable to dispensary surveillance.

The most common chronic diseases in our study were cardiovascular diseases (CVD-ischemic heart disease, hypertension, etc.), followed by endocrinology diseases. This is consistent with the data that Bulgaria has the highest incidence and mortality of CVD in Europe (60\% of all deaths in our country are the result of stroke and coronary heart disease) (Mateva \& Nonchev, 2015; Finegold, Asaria \& Francis, 2013).

In Bulgaria dispensary observation is a method for actively monitoring the dynamic impact on the health of pregnant women and patient groups especially with chronic diseases. This is a method of 
active search, dynamic monitoring, diagnosis and rehabilitation, medical and social adaptation (Dimcheva \& Mateva, 2015). The implementation of these health activities provides guaranteed access to each insured person a volume of preventive actions aimed at early detection of risk factors for developing the disease, early diagnosis of the disease and timely referral for treatment in order to prevent permanent damage or an unfavorable outcome. These activities are consistent with the objectives and priorities of the Bulgarian health policy implemented by the Ministry of Health aimed at improving the health status of the population and reducing morbidity and mortality by strengthening health promotion, and the primary and secondary prevention of diseases (Ministry of Health, promulgated in State Gazette number 106 of December 3, 2004; Levterova et al., 2013).

\begin{tabular}{|c|c|c|c|c|c|}
\hline & & & & & \multirow[b]{4}{*}{$\mathrm{P}$} \\
\hline & \multirow{2}{*}{\multicolumn{2}{|c|}{$\frac{\text { Male, n (\%) }}{20(24,4 \%)}$}} & \multirow{2}{*}{\multicolumn{2}{|c|}{$\begin{array}{c}\text { Female, n (\%) } \\
62(75,6 \%)\end{array}$}} & \\
\hline & & & & & \\
\hline & Mean & (SD) & Mean & (SD) & \\
\hline Age (years) & 56.3 & $(17.66)$ & 55.39 & $(16.75)$ & 0.835 \\
\hline \multicolumn{6}{|l|}{ Chronic diseases } \\
\hline Cardiovascular diseases, $\mathrm{n}(\%)$ & \multicolumn{2}{|c|}{$13(16 \%)$} & \multicolumn{2}{|c|}{$29(35 \%)$} & 0.03 \\
\hline Cancer, n (\%) & \multirow{2}{*}{\multicolumn{2}{|c|}{$\frac{2(3 \%)}{4(5 \%)}$}} & \multirow{2}{*}{\multicolumn{2}{|c|}{$\frac{3(4 \%)}{15(18 \%)}$}} & 0.591 \\
\hline Endocrinology diseases, n (\%) & & & & & 0.771 \\
\hline Respiratory diseases, n (\%) & \multicolumn{2}{|c|}{$1(1 \%)$} & \multicolumn{2}{|c|}{$5(6 \%)$} & 1.00 \\
\hline Other, n (\%) & \multicolumn{2}{|c|}{$0(0.00 \%)$} & \multicolumn{2}{|c|}{$10(12 \%)$} & 1.00 \\
\hline \multicolumn{6}{|l|}{ Employment } \\
\hline Employed, n (\%) & \multicolumn{2}{|c|}{$10(12 \%)$} & \multicolumn{2}{|c|}{$29(35 \%)$} & 0.288 \\
\hline Unemployed, n (\%) & \multirow{2}{*}{\multicolumn{2}{|c|}{$\frac{2(2 \%)}{8(10 \%)}$}} & \multirow{2}{*}{\multicolumn{2}{|c|}{$\frac{3(4 \%)}{30(37 \%)}$}} & 1.00 \\
\hline Retired, n (\%) & & & & & 0.609 \\
\hline \multicolumn{6}{|l|}{ Income } \\
\hline Very low, n (\%) & \multicolumn{2}{|c|}{$11(15 \%)$} & \multicolumn{2}{|c|}{$39(48 \%)$} & 0.602 \\
\hline Low, n (\%) & \multicolumn{2}{|c|}{$1(1 \%)$} & \multicolumn{2}{|c|}{$10(12 \%)$} & 0.279 \\
\hline Middle, n (\%) & \multicolumn{2}{|c|}{$8(10 \%)$} & \multirow{2}{*}{\multicolumn{2}{|c|}{$\frac{8(10 \%)}{4(4 \%)}$}} & 0.01 \\
\hline High, n (\%) & & $0 \%)$ & & & 1.00 \\
\hline \multicolumn{6}{|l|}{ Source: Authors } \\
\hline
\end{tabular}

The original questionnaire is using the traditional five-Likert scale from "excellent" to "very bad" for "general health". Analysis of the responses showed that the majority of respondents accepted his/her condition as "good" - 55\% (41) and 22\% (16) as "bad". The distribution of answers by nosological groups is given in Figure 1.

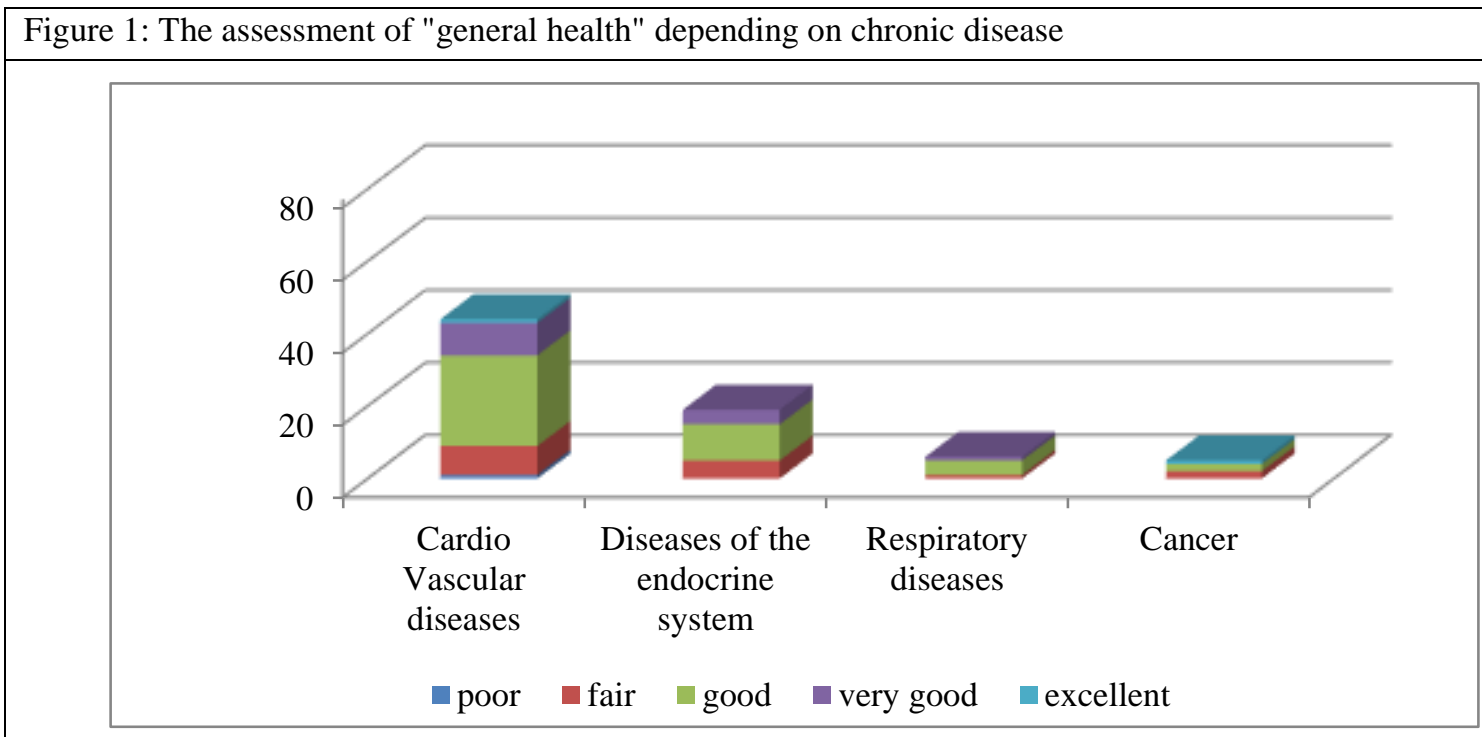

Source: Authors 
There were statistically significant differences in the assessments of "general health" in different groups of participants by gender $(\chi 2=16.65, \mathrm{P}<0.002)$, age $(\chi 2=12.57, \mathrm{P}<0.05)$ and social status $(\chi 2=28.54, \mathrm{P}<0.0001)$.

The analysis of the data by using a questionnaire showed that age, gender, and social status are important factors affecting self-esteem "general health." This fact allows for the creating of a specific profile of patients and their needs using appropriate approaches to health education (Arnold et al., 2004).

The difference in quality of life between the sexes is well expressed in this study - female individuals have worse QoL. This is consistent with the reported gender differences in QoL in the general population and in studies involving patients with chronic diseases (Fayers \& Machin, 2013).

\section{Conclusion}

There are a few studies on the Health-Related Quality Of Life of patients with chronic diseases in Bulgaria, which seriously limits the possibility of an objective assessment of the effectiveness of medical and medico-social assistance for these patients. Health-related quality of life is a measurable element and for quantifying of its objectification different scales may be used (Garratt et al., 2002; Bradley, 2001).

Subjective assessment of health is a factor that has a strong impact on the quality of life of patients and is an important component in evaluating the effectiveness of provided health care for patients with NCDs. Data reported by the patients is important for health professionals as feedback on the care. Patient-reported health assessments results offer a great potential for improving the quality and outcomes of health services.

Analysis of the results from the measurement of quality of life in patients with NCDs can be used to determine the priorities of health and social policies in these groups of people which could lead to better medical care and improve the quality of life in patients with NCDs. Integrated measurements of quality indicators will provide a comprehensive assessment of the management of NCDs. Introducing these innovations in health policies will improve health care and reduce the clinical and financial burden of these diseases.

\section{Acknowledgments}

The present study was funded by the Medical University - Plovdiv within the project № - NO 04/2012 "Public Health. Monitoring of chronic diseases - a multidisciplinary approach."

\section{Reference}

Arnold, R., Ranchor, A., Sanderman, R., Kempen, G., Ormel, J., Suurmeijer, T. (2004). The relative contribution of domains of quality of life to overall quality of life for different chronic diseases. Quality of Life Research. 13(5): 883-896. DOI:10.1023/B:QURE.0000025599.74923.f2.

Bradley, C. (2001). Importance of differentiating health status from quality of life. The Lancet. 357:7-8. DOI: 10.1016/S0140-6736(00)03562-5.

Busse, R., Blümel, M., Scheller-Kreinsen, D., Zentner, A. (2010). Tackling chronic disease in Europe: strategies, interventions and challenges. No. 20. WHO Regional Office Europe. Available from: http://www.euro.who.int/_data/assets/pdf_file/0008/96632/E93736.pdf.

CDC. Measuring Healthy Days. Atlanta, Georgia: CDC; 2000. Available from: https://www.cdc.gov/hrqol/pdfs/mhd.pdf

Dimcheva, T., Foreva, G., Asenova, R., Mateva, N., Stoev, T., Dimova, R. (2015). The role of patients in the management of chronic diseases: results of the focus-group study. European Medical, Health and Pharmaceutical Journal. 8(2). DOI: http://dx.doi.org/10.12955/emhpj.v8i2.690.

Dimcheva, T., Mateva, N. (2015). Non-communicable chronic disease management-good practices and models. International Journal Scientific and Applicative papers. 8(2): 181-185. (In Bulgarian)

Fayers P, Machin D. (2013). Quality of life: the assessment, analysis and interpretation of patient-reported outcomes. John Wiley \& Sons.

Finegold, J. A., Asaria, P., \& Francis, D. P. (2013). Mortality from ischaemic heart disease by country, region, and age: Statistics from World Health Organisation and United Nations. International Journal of Cardiology, 168(2), 934-945. http://doi.org/10.1016/j.ijcard.2012.10.046.

Fortin, M., Lapointe, L., Hudon, C., Vanasse, A., Ntetu, A. L., \& Maltais, D. (2004). Multimorbidity and quality of life in primary care: a systematic review. Health and Quality of Life Outcomes, 2, 51. http://doi.org/10.1186/1477-7525-2-51.

Garratt, A., Schmidt, L., Mackintosh, A., \& Fitzpatrick, R. (2002). Quality of life measurement: bibliographic study of patient assessed health outcome measures. BMJ : British Medical Journal, 324(7351), 1417. 
Goodman, R. A., Posner, S. F., Huang, E. S., Parekh, A. K., Koh, H. K. (2013). Defining and Measuring Chronic Conditions: Imperatives for Research, Policy, Program, and Practice. Prev Chronic Dis.10. DOI: http://dx.doi.org/10.5888/pcd10.120239.

Levterova B., Dimitrova D., Raicheva R., Jambov A. (2013). Health needs assessment - Family Physicians' perspectives on priorities and target groups in primary care practices in Bulgaria. Euras J Fam Med. 2 (1): 19-24.

Levterova B, Foreva G, Dimitrova D, Assenova R. (2014). Use of instruments for assessing the quality of life in chronic diseases in Bulgarian medical practice. General Medicine. 16 (2): 12-18. (In Bulgarian)

Lim, S. S., Vos, T., Flaxman, A. D., Danaei, G., Shibuya, K., Adair-Rohani, H., ... Ezzati, M. (2012). A comparative risk assessment of burden of disease and injury attributable to 67 risk factors and risk factor clusters in 21 regions, 1990-2010: a systematic analysis for the Global Burden of Disease Study 2010. Lancet, 380(9859), 2224-2260. http://doi.org/10.1016/S0140-6736(12)61766-8.

Mateva N, Nonchev B. (2015). Chronic diseases monitoring-key aspects and problems. Knowledge International Journal Scientific and Applicative papers. 8/2: 48-52. (In Bulgarian)

Nutbeam, D. (1998). Health promotion glossary. Health promotion international. 13(4): 349-364.

Ordinance № 39 of November 16, 2004 for prophylactic examinations and dispensary, 01.01.2005 issued by the Ministry of Health, promulgated in State Gazette number 106 of December 3, 2004. (In Bulgarian)

Preamble to the Constitution of the World Health Organization as adopted by the International Health Conference, New York,19-22 June, 1946; signed on 22 July 1946 by the representatives of 61 States (Off. Rec. Wld Hlth Org., 2, 100), and entered into force on 7 April 1948. Amendments adopted by the Twenty-sixth, Twenty-ninth, Thirty-ninth and Fifty-first World Health Assemblies (resolutions WHA26.37, WHA29.38, WHA39.6 and WHA51.23) came into force on 3 February 1977, 20 January 1984, 11 July 1994 and 15 September 2005. The Definition has not been amended since 1948. Available from: http://www.who.int/governance/eb/who_constitution_en.pdf.

WHO. (2008). How can chronic disease management programmes operate across care settings and providers? World Health Organization and World Health Organization, on behalf of the European Observatory on Health Systems and Policies 2008 Copenhagen , Denmark. Available from: http://apps.who.int/gb/archive/pdf_files/WHA53/ResWHA53/17.pdf.

World Health Organization. (2014). Global status report on noncommunicable diseases 2014. 